Managers attempt to hijack community medicine

DAVID ST GEORGE

In a recent leading article on Griffiths in action the British Medical fournal suggested that the tabloid headline might have been "Administrators hijack NHS." Hence the title for this article, which captures the essence of my experience of a course held at the King's Fund College. This was the introductory week of a two year training programme for registrars in community medicine; most of the week was devoted to management.

Many of us are well aware of the unresolved debate about whether community physicians are applied epidemiologists, practitioners of public health and preventive medicine, or health service managers. So I found the emphasis of the course somewhat surprising. It was as if the debate had been resolved in favour of the managers. Indeed, there is a faction in community medicine that argues that community physicians should become managers if only to rectify the current position of "management without doctors." Much of the power in the National Health Service now lies with the unit, district, and regional general managers. If community physicians could be trained for these posts and if they could be successfully appointed to them perhaps the hijack of the NHS by administrators could be overturned.

While there may be some merit in this approach it also has its dangers. Firstly, there are constraints on managers that could force them to make decisions that go against medical opinion even if they were doctors. Appointing community physicians to management posts may therefore merely result in a gain for management and a loss for the medical profession. Secondly, setting the target for community medicine as a takeover of management posts may distract attention from alternative solutions to the hijack, in particular those that could expose and take advantage of weaknesses in the new management arrangements. For example, management accountability is not so clear cut in the NHS as it is in the commercial world (the source of Griffiths management ideas). Indeed, it is not as strong in the post-Griffiths NHS as Griffiths himself proposed in his report. ${ }^{3}$ If community physicians concentrated on using their professional skills to evaluate the effects of management decisions on the health service, on patients, and on the community this might force managers to take the views of local professionals more seriously.

I would therefore like to propose an alternative role for community medicine in the post-Griffiths NHS-namely, one that could hold managers to account for the way that their decisions affect the health service and the health of the community. But we need to look first at the flaws that have appeared in the Griffiths model of management that justify community physicians taking on this role.

\section{“Chessmaster" model of management}

The idea of focusing the NHS's general management function on individual managers comes from the commercial world. In a hostile and competitive environment, where financial survival of the organisation is at stake, it is far more efficient for power to be concentrated on an individual who identifies with the overall goal of the organisation (maximising profits) but who can also take

South West Thames Regional Health Authority, London W2 3QR

DAVID ST GEORGE, MB, CHB, registrar in community medicine

Correspondence to: 38 Weston Park, Crouch End, London N8 9TJ. personal responsibility for short term decisions. The financial environment fluctuates from day to day; unexpected competition comes on to the market; decisions have to be made in the face of uncertainty, ambiguity, and conflicting advice; risks have to be taken; subordinates have to be controlled; board members have to be convinced of the wisdom of management decisions; and so on. Indeed, the behaviour of successful business managers in this environment was likened (by one of the King's Fund trainers) to that of a chess player keeping the goal of winning (profits) always to the fore but taking short term decisions in relation to immediate fluctuations in fortune. In this way managers keep the upper hand in the face of immediate hostility, unexpected events, and uncertainty about the future.

For this "chessmaster" model to work in a commercial organisation the manager must become highly individualistic, egoistic, autocratic, and confident of winning. He must exercise as much control as possible over his "chess pieces," which even includes manipulating his "bosses" (the board members) so that he can use their authority to his advantage. ${ }^{4}$ The price for this autonomy and autocracy, however, is ultimate personal accountability to the board for the financial performance of the organisation. If the manager does not "win" for his organisation he loses his job. There is also a form of "outward" accountability to his customers: if customers are not satisfied with the goods and services sales will fall and the financial viability of the organisation will be threatened (along with the manager's job).

This model has been grafted on to the NHS with two consequences. Firstly, the idea of management accountability narrowly defined in terms of financial accountability has been accepted without question. The balance of profit and loss accounts is the ultimate goal of commercial organisations, but the NHS should surely be ultimately concerned with health outcomes. If the general manager model is to be completely adapted to the NHS, which Griffiths hoped, managers should be made personally responsible for health outcomes. Where in the NHS has this view been taken? Secondly, outward accountability to health service "customers" has barely been considered. This is largely because assessing the community's health needs and seeking consumer views of the quality of care often expose deficiencies in services that require an increase in resources. This clearly conflicts with the need to stay within tight cash limits.

The checks and balances that justify the transient autocracy of managers in the business world are thus lost when this individualistic style of management is transposed into the NHS. Upward accountability tends to be in financial rather than health terms and outward accountability is only marginally considered. I do not believe that this was the real intention of the Griffiths inquiry, but it seems to suit the Department of Health and Social Security and the Treasury. If the government considers the ultimate goal of the NHS to be working to tight cash limits and reducing public expenditurethat is, financial rather than health goals - then the "chessmaster" model of commercial management is ideal. Giving the bulk of the power in each district health authcrity to an individualistic, autocratic "chess master," accountable to the authority (and the DHSS) primarily in financial terms, makes the battle of closing hospitals and challenging the power of doctors much easier to win. The "chess master" can, for example, play off one group of consultants against another, or the general practitioners against the consultants, in order to divide his "enemies" and increase his advantage in the "chess game." So long as the goal of staying within cash limits is always kept in mind it does not really matter which strategy is used by the "chess master" for making savings. He can take a detached, disinterested view of the particular "chess pieces" in 
his game-for example, professionals, patients, unions, health authority members, interest groups-and back whichever groups will maximise his ability to win.

In this game the background of the manager-doctor, nurse, administrator-is clearly immaterial. When the goal is defined in financial terms, and an individualistic style of management is demanded, the same range of decisions will be taken by the manager, otherwise he would lose his job.

\section{Solution for community physicians}

Rather than setting their sights on taking over management posts community physicians should perhaps consider using their existing positions in the NHS to help change the current system of management accountability. Using their skills in epidemiology, and the direct access that they have to the health authority for professional matters, community physicians could provide the authority with the necessary information to compensate for the present lack of upward and outward accountability.

Outward management accountability could be achieved by gathering the views of service users and community interest groups about specific management proposals and about changes that have been made in service provision. Upward accountability (in health rather than financial terms) could be achieved by assessing the population's health needs and evaluating the degree to which particular services meet them.

With this information health authorities would be in a position to assess management performance, both in terms of whether managers have taken into account consumers' views and the community's health needs when making their decisions, and in terms of the impact that these decisions subsequently have on patients and on the community. For example, managers often use lower throughput in a hospital (compared with other hospitals in the district) as justification for closing beds in the "less efficient" hospital. Consultants are then forced to become more "productive" in order to cope with the same level of demand. No untoward effects allegedly result from this reduction in resources because the "inefficient" consultants are simply brought into line with their "more efficient" colleagues in other hospitals.

Comparatively lower throughput in a hospital, however, can be caused by several factors besides "less productive" consultants. For example, there may be a higher proportion of elderly patients or patients with conditions that require a longer stay in hospital. On the other hand, discharge into the community may be hampered by insufficient community services or because of a socially disadvantaged catchment area. A community physician could be given responsibility for investigating the reasons for the lower throughput before a management decision is taken about closing beds. If beds are to be closed the community physician can be given the added responsibility of monitoring the effects of the closure and of determining whether or not the aim of increasing productivity without untoward effects is in fact met.

\section{Research and evaluation skills}

When carrying out such tasks for the health authority community physicians would use their research and evaluation skills to gather, collate, and interpret information. Many community physicians have defined their post-Griffiths role in terms of these skills, but they tend to see themselves simply as assistants to managers. This contribution to management decision making is necessary, but experience has shown that managers do not always heed the findings of research projects undertaken by community physicians. It is vital, therefore, that a channel for direct communication between community physicians and the health authority is opened and maintained so that the authority can be fully informed of the complete background and justification for management decisions.

Although community physicians would be gathering the views of service users in these investigations, this must not be seen as a substitute for community health councils. An employee of the authority cannot replace the community health council's direct and informed commentary on services from the patient's perspective. Indeed, part of the community physician's task would be to assess whether managers have taken into account the views of the community health council.

Community physicians are also not being asked to become "guardians of the public health." This approach runs the risk of creating a paternalistic élite who try to impose their personal opinions on managers because they know what is best for the community. The health authority should be the guardian of the public health and community physicians should furnish health authority members with information that enables them to plan and provide services to the greatest benefit of the public.

Perhaps it goes without saying that managers are unlikely to look favourably on a community accountant role for community physicians. The Griffiths report, however, calls for this type of management accountability. Griffiths considers the experience and perceptions of patients and the community to be central to formulating policy and to planning, delivering, and monitoring services (section 13 of the report's recommendations). Real output measurements are also intended to be a major concern of management at all levels (section 7 of the report's general observations). These aspects of the Griffiths inquiry tend to be glossed over by the new general managers. Perhaps this is because they contain the very moves that could lead to "checkmate" by patients and the community.

\section{References}

1 Anonymous. Griffiths in action: not what the doctor ordered. $\mathrm{BrMed} \mathcal{f} 1985 ; 291: 843-4$ 2 Ellis N. Managing without doctors: realities of Griffiths. $\mathrm{Br} \mathrm{Med} \mathcal{F}$ 1985;291:837-8.

3 NHS Management Inquiry. Report. London: DHSS, 1983. (Griffiths report.)

4 Galbraith JK. The Anatomy of Power. London: Transworld, 1984.

5 Eskin F. Guardians of the public health. Health and Social Services fournal 1985 October 24: $1328-9$

(Accepted 13 November 1985)

\section{THIRTY YEARS AGO}

\section{Doctors and the Press}

SIR, - "Recommended routine procedure at hospitals" concerning information to the press, which has been produced by a conference of representatives of the medical profession and the press, contains statements and assumptions which are not explained by the memorandum which accompanies it (Supplement, October 29, p. 100).

It is not made at all clear why the "vitally important" good personal relations between hospitals and local press must be fostered by the hospitals handing out information regarding individual patients. It is the function of the hospital, as it is of the doctor, to treat and care for patients and restore them to health. One might well understand that included in this is a duty to inform the patient and the patient's relatives of his progress. The objects of those who own newspapers are various and sometimes difficult to understand, but it is much to be doubted whether they are in any respect the same as those of a hospital. I submit that it is no part of the duty of a hospital to give information for publication in newspapers. There are, it is clear, occasions, such as accidents in which many people are involved, when the newspapers can perform a valuable service in informing and identifying relatives, but this service is customarily performed by the police, and it would surely be better for the hospitals to inform the police and for the police to release information for publication, when it is in the public interest. In any case, if a patient or his relatives wish a bulletin to be published, surely they themselves can inform the press without expecting the hospital to act as a press agency. To add such a task to the already overburdened staff of our hospitals is reduced to absurdity by the recommendation that all hospitals should nominate a "senior and responsible officer" to be available at all times to answer press inquiries.-I am, etc.,

F. RAY BeTtLeY

London, $\mathbf{W} .1$

(British Medical fournal 1955;ii:186.) 